\title{
SocArXiv
}

Preprint : November 20, 2021

URL/DOI GOES HERE

\section{Parental Involvement and Depressive Symptoms among Adolescents}

\author{
Ksenia Pavlenko \\ HSE University \\ kpavlenko@hse.ru
}

\author{
Alexandra Bochaver \\ HSE University \\ abochaver@hse.ru
}

\author{
Elizaveta Sivak \\ HSE University \\ esivak@hse.ru
}

\author{
Ivan Smirnov \\ HSE University \\ ibsmirnov@hse.ru
}

\begin{abstract}
Adolescent depression is an increasingly important problem in modern society. One of the key determinants of adolescent depression is parental involvement. It has been established that parental involvement and high-quality parent-child relationships play a protective role in psychosocial well-being of children while parental neglect and abuse are risk factors for depression. However, different forms of parental involvement might have different effects on children's psychological well-being. In particular, some kinds of parental control may have adverse effects. In this paper, we study the association between parental control and positive parental involvement with depression using survey data of middle and high school students from a Russian region $(N=1364)$. We find that, independently, all forms of parental involvement are negatively associated with depression. However, only positive involvement is a protective factor against depression, while parental control is not associated with depression after controlling for the other forms of parental involvement. These results could be used in developing prevention and education programs for parents.
\end{abstract}

Keywords: parental involvement, adolescence, depression, protective factors, parental control

\section{Introduction}

Depression is one of the leading causes of illness and disability among adolescents (WHO 2008). About 13\%-17\% of adolescents aged 12-15 report symptoms of depression, and about $8.6 \%$ report having seriously considered suicide in the past year (Bitsko et al. 2018; Lawrence et al. 2015). Preventing depression requires a better understanding of associated protective and risk factors.

One of the key determinants of depression is the family context. It is well known that 
parental involvement and parent-child relationships impact adolescents' well-being. Different forms of family interactions such as parental involvement (Tammariello et al. 2012), relations satisfaction (Chen et al. 2019), or common activities (Lambert et al. 2014) play an important role in the children's depression and other psychosocial outcomes. High levels of parental involvement (homework control, monitoring of free time, and seeking to understand children's problems) are associated with significantly lower odds of depression and suicidal thoughts for both boys and girls (Tammariello et al. 2012).

Adolescents who are satisfied with their parent-child relationships are at lower risk of mental illness and report higher emotional well-being (Chen et al. 2019; Davids et al. 2017; Yap et al. 2014). Children's happiness is positively associated with good connections with family, friends, peers, and teachers at school (Lambert et al. 2014). Parental warmth, monitoring, effective and consistent discipline, and good family communication and help protect a child from depression and support their emotional well-being (Brent et al. 2009; Sheeber et al. 2007; Chen et al. 2019).

At the same time, impaired parent-child dynamics may be related to the progress of depressive disorder in adolescence. Such factors as parental abuse and neglect, low attachment, lack of warmth, and inter-parental conflict increase the risk of depression, lead to lower recovery rate from depression, and increase likelihood of (attempted) suicide among adolescents (Yap et al. 2014; Rueter et al. 1999; Stice et al. 2004; Hale et al. 2008; Rengasamy et al. 2013; Dardas et al. 2018; Norman et al. 2012).

While the relationship between parental involvement and depression is well established, the role of parental control is less clear and the evidence is contradictory. In relation to control, several constructs are discussed: parental knowledge - knowledge about where children are, and what and with whom they do; parental monitoring, including active surveillance and covert control of children's activity, plans, relationships, friendships, etc. (Walters 2019); and parental control - a set of practices that are implemented to ensure that the activities of the child for specific requirements [Grolnick, Pomerantz, 2009].

In studies of the early and mid-20th century, parental control was understood primarily as dominance, interference and pressure exerted by parents on a child, but later the concept was developed, and now is understood as a set of parental practices implemented to ensure that the child's activity meets certain requirements (Grolnick and Pomerantz 2009). Researchers often distinguish between psychological control (influencing the feelings and thoughts of a child, attempts to interfere in his psychological and emotional development) and behavioral control (guiding the actions of a child, regulating his behavior through requirements and setting rules) (Barber, 1996). A closely related concept is parental monitoring which includes active supervision and covert monitoring of children's activities, plans, friendships, time spent doing homework, watching TV, home conditions conducive to learning, the need to come home after school etc. (Walters 2019).

Some studies find the positive contribution of parental control to the children's well-being. For example, a survey of 17,643 Finnish adolescents showed that the less parents knew about the whereabouts and friends of their children, the more common were the depressive symptoms (anxiety, psychosomatic symptoms and other maladjustment outcomes) (Fröjd et al. 2007). On the other hand, it was found that there are different types of control, and parental use of psychological control (understood as intrusiveness, pressure, induction of the feelings of guilt and shame, conditional love, etc.) could damage the sense of safety, decrease self-esteem, and 
lead to depression. It is perceived by children not as a form of care and close relationships, but as a patronizing, persistent, egoistic, controlling communication style provoking the feeling of guilt (Barber and Harmon 2002; Soenens and Vansteenkiste 2010).

In this paper, we explore how parental control and other kinds of parental involvement are associated with depressive symptoms among adolescents. The study was conducted in the Republic of Sakha (Yakutia), a large region in north-eastern Siberia (Russia).

\section{Data and Methods}

\section{Participants and procedures}

The study is based on the survey of school students of one municipal district in the Republic of Sakha (Yakutia), Russia, a mostly rural, sparsely populated region. Participation in the survey was voluntary. Every school in the district received an invitation to participate in the survey with the link to an online questionnaire.

Students from the 5th-11th grades (11-17 years old), from all the district's schools were informed about the study. We recommended that school principals gather students in computer classes in order for students to fill in the questionnaires, so that everyone had the opportunity to participate in the survey, regardless of whether they had a computer or internet access at home. The school administration and parents did not have access to the students' answers. At the beginning of each questionnaire, the respondents were presented with an informed consent form. If the respondents did not agree with the terms of participation in the study, they could not fill out the questionnaire. In total, 1364 students completed the questionnaire $(56 \%$ girls), which is $46 \%$ of all students in grades 5-11 in the district. Among the respondents, $16 \%$ studied in the 5 th grade, $16 \%$ - in the 6 th grade, $16 \%$ - in the 7 th grade, $13 \%$ - in the 8 th grade, $16 \%$ - in the 9 th grade, $11 \%$ - in the 10 th grade and $12 \%$ - in the 11 th grade.

\section{Measures}

\section{Depression}

We used the Patient Health Questionnaire scale (PHQ-8), which is used to assess the severity of depressive symptoms (Spitzer et al. 1999). Several studies show that it has good sensitivity and specificity for detecting depressive disorders (Kroenke et al. 2010; Wells et al. 2013). It includes eight items, each of which is scored from 0 to 3 , generating a severity score of 0 to 24. Scores of 5, 10, 15, and 20 represent the cut-off points for mild, moderate, moderately severe and severe depression, respectively.

\section{Parental involvement}

We measured two aspects of parental involvement: positive parenting practices and parental control. To measure positive parenting practices we used a scale based on the Alabama Parenting Questionnaire (Shelton et al. 1996). Participants were asked about the frequency of four activities on a 5-point scale (from 0 - "never" to 5 - "every day"): help with homework, common activities with parents, friendly conversations, and conversations about school. 
Table 1: Indicators of Parental involvement Question Scale

\begin{tabular}{|c|c|}
\hline \multicolumn{2}{|c|}{ Positive parenting practices } \\
\hline $\begin{array}{l}\text { Help with } \\
\text { homework }\end{array}$ & $\begin{array}{l}\text { "Your parents help you } \\
\text { with homework when } \\
\text { you have difficulties" }\end{array}$ \\
\hline $\begin{array}{l}\text { Common } \\
\text { activities }\end{array}$ & $\begin{array}{l}\text { "You take part in in- } \\
\text { teresting activities with } \\
\text { your parents" }\end{array}$ \\
\hline $\begin{array}{l}\text { Conversations } \\
\text { about school }\end{array}$ & $\begin{array}{l}\text { "Your parents ask about } \\
\text { your day at school" }\end{array}$ \\
\hline $\begin{array}{l}\text { Friendly con- } \\
\text { versations }\end{array}$ & $\begin{array}{l}\text { "Your parents friendly } \\
\text { chat with your" }\end{array}$ \\
\hline \multicolumn{2}{|l|}{ Parental control } \\
\hline $\begin{array}{l}\text { Homework } \\
\text { control }\end{array}$ & $\begin{array}{l}\text { "Your parents } \\
\text { sure you ye } \\
\text { homework" }\end{array}$ \\
\hline $\begin{array}{l}\text { Control over } \\
\text { the use of } \\
\text { gadgets }\end{array}$ & $\begin{array}{l}\text { "Does your family have } \\
\text { any rules about the time } \\
\text { during which you can: } \\
\text { watch TV / use a smart- } \\
\text { phone / use a tablet } \\
\text { / watch a video (on } \\
\text { a smartphone, tablet, } \\
\text { computer) / play com- } \\
\text { puter games?" }\end{array}$ \\
\hline
\end{tabular}

Never / once a month or less often / once every 1 or 2 weeks / several times a week / daily

Never / once a month or less often / once every 1 or 2 weeks / several times a week / daily

The number of rules in the family regarding the time of using gadgets (score from 0 to 5 )

We measured two activities related to parental control: parental control over homework and control over the use of gadgets. Students were asked a series of yes-no questions about the rules related to the use of gadgets. We then computed the total number of gadget-use related rules in the household. The degree of agreement between questions regarding the use of gadgets was 0.816 (Cronbach's Alpha).

All indicators of parental involvement are presented in Table 1.

\section{Results}

According to the PHQ- 8 scale, $15.3 \%$ of respondents have moderate symptoms of depression (10-14), 5.9\% moderately severe (15-19) and $2.1 \%$ severe (20-24). The level of depression symptoms of students in this sample is consistent with results from other studies which re- 
Table 2: Correlations between depression score and parental involvement indicators (we used Spearman's correlation coefficient because Indicators of parental involvement are measured on an ordinal scale)

\begin{tabular}{ll} 
Indicators of parental involvement & Spearman's $\rho[95 \% \mathrm{CI}]$ \\
\hline Help with homework & $-0.245^{* *}[-0.300 ;-0.190]$ \\
Common activities & $-0.267^{* *}[-0.322 ;-0.212]$ \\
Conversations about school & $-0.161^{* *}[-0.218 ;-0.104]$ \\
Friendly conversations & $-0.215^{* *}[-0.270 ;-0.160]$ \\
Homework control & $-0.172^{* *}[-0.229 ;-0.115]$ \\
Control over the use of gadgets & $-0.130^{* *}[-0.185 ;-0.075]$ \\
\hline$* * *-P<0.001$ &
\end{tabular}

ported the prevalence of moderate/moderately severe/severe depression to be 17-28\% (Leung et al. 2020; Tsehay et al. 2020; Burdzovic and Brunborg 2017). Consistent with the results of previous studies (Leung et al. 2020; Burdzovic and Brunborg 2017), symptoms of moderate, moderately severe and severe depression are more prevalent among high school students (grades 8-11, 14-17 years old) than among middle school students (grades 5-7, 11-13 years old; (28.4\% vs $17.9 \%$ ) (Young et al. 2010), and among girls (30.8\% vs $14.3 \%$; on average the depression score is higher for girls (7.4 vs 5.3, $P<0.001)$ ).

We find that the severity of depressive symptoms is correlated with all measures of parental involvement. Stronger parental involvement is associated with a lower level of depression symptoms (see Table 2). The strongest associations are observed in the cases of the frequency of common activities and help with homework.

Our results and previous research show that symptoms of depression tend to increase with age (Young et al. 2010), while the level of parental involvement (in particular, school involvement) decreases (Im et al. 2016). We analyze associations between parental involvement and depression separately for different age groups to make sure that the association is not explained by age as a confounding factor. Analysis by age shows that significant relationships remain for almost all measures of parental involvement (see Table 3).

In order to uncover a potential role of different types of parental involvement, we conducted an exploratory factor analysis ${ }^{1}$ of those indicators that were measured uniformly on a fivepoint scale. Using the method of principal components, we have identified three factors that explain $79 \%$ of the variance. Factor loadings (Varimax rotation) are shown in Table 4.

We defined three factors to distinguish different types of parental involvement. Factor 1 "Help and common activities" is associated with the most resource-intensive positive parenting practices: helping with homework and engaging in common activities with a child. Factor 2 "Friendship with a child" combines positive parenting practices that are supposedly less timeconsuming for a parent and are associated with maintaining friendly relations with the child, interest in their activities and life (conversation about school and friendly conversations).

\footnotetext{
${ }^{1}$ The possibility of classical factor analysis on ordinal variables is based on the proximity of correlation matrices. The average relative difference in the values of the Pearson and Kendall correlation coefficients is less than $15 \%$.
} 
Table 3: Correlations between depression score and indicators of parental involvement for different age groups

Spearman's correlation coefficient

Indicator of parental involvement $\quad$ grades 5-7 $\quad$ grades 8-9 grades 10-11

Help with homework

$-0.158^{* *}-0.264^{* *} \quad-0.255^{* *}$

Common activities

$-0.219^{* *} \quad-0.271^{* *} \quad-0.341^{* *}$

Conversations about school

$-0.140^{* *}-0.223^{* *} \quad-0.135^{*}$

Friendly conversations

$-0.185^{* *}-0.228^{* *} \quad-0.243^{* *}$

Homework control

$-0.164^{* *}-0.130^{*} \quad-0.145^{*}$

Control over the use of gadgets

$-0.083-0.114^{*}-0.143^{*}$

** $-P<0.01,{ }^{*}-P<0.05$

Table 4: Values of factor loadings

\begin{tabular}{lrrr} 
Indicators of parental involvement & \multicolumn{1}{c}{1} & \multicolumn{1}{c}{2} & \multicolumn{1}{c}{3} \\
\hline Homework control & 0.234 & 0.114 & $\mathbf{0 . 9 2 8}$ \\
Common activities & $\mathbf{0 . 8 0 3}$ & 0.317 & 0.077 \\
Help with homework & $\mathbf{0 . 8 0 8}$ & 0.099 & 0.311 \\
Conversations about school & 0.083 & $\mathbf{0 . 8 4 5}$ & 0.274 \\
Friendly conversations & 0.350 & $\mathbf{0 . 7 6 7}$ & -0.085 \\
\hline
\end{tabular}


Table 5: Severity of depressive symptoms regressed on different types of parenting involvement, child's grade and gender

\begin{tabular}{lrrr} 
& B & S.E. & \multicolumn{1}{c}{ P } \\
\hline (Constant) & 4.230 & 0.669 & $<0.001$ \\
Year of studies & 0.162 & 0.075 & 0.031 \\
Gender (1 - girls; 0 - boys) & 2.059 & 0.279 & $<0.001$ \\
Factor "Help and common activities" & -1.107 & 0.142 & $<0.001$ \\
Factor "Friendship with a child" & -0.823 & 0.137 & $<0.001$ \\
Factor "Educational control" & -0.228 & 0.142 & 0.109 \\
Control over the use of gadgets & -0.066 & 0.088 & 0.451 \\
\hline
\end{tabular}

$$
R^{2}=0.137 ; \text { Adjusted } R^{2}=0.133 ; F=31.354(P<0.001) ; N=1189
$$

Factor 3 "Educational control" is most strongly associated with the practice of controlling and regulating parenting behavior: control over homework.

In order to analyze the effects of the identified types of parental involvement and variables that were not included in the factor model on depressive symptoms we built an OLS linear regression model.

The results demonstrate that after controlling for positive parenting practices the association between controlling practices and depressive symptoms becomes insignificant (see Table 5). This applies both to the "Educational control" factor and to the variable "Control over the use of gadgets". At the same time the association between positive parenting practices and depressive symptoms is negative and significant.

\section{Conclusions}

In this paper we analyzed how different types of parental involvement, positive parenting practices and parental control are associated with depressive symptoms in adolescents. Our results indicate that the severity of depressive symptoms is associated with all measured indicators of parental involvement. Children whose parents are more involved tend to be less depressed. The strongest correlations are found in case of the most resource-intensive types of parental involvement: help with homework and engaging in common activities with a child. Indicators of good parent-child relationships (practices of friendly conversations with a child, and conversations about school) and practices of parental control are also negatively correlated with depression. However, these associations are weaker. After controlling for other types of parental involvement, the association of practices of parental control with depressive symptoms becomes insignificant.

In this study we considered only two types of parental control: control over homework and control over the use of gadgets. The control over other areas of the child's life could be differently associated with depression. It is also important to note that we considered only the presence or absence of controlling practices without examining how exactly they are carried out. According to some studies (Barber and Harmon 2002; Soenens and Vansteenkiste 2010), 
different types of control can have different effects on the psychological well-being of children. It should be also noted that we only consider the correlation between parental involvement and the depression and this design does not allow to establish a causal link between variables. While our results could be considered as an indication that parental involvement affects children, it is important not to forget about the potential for reverse causation: good childhood outcomes make parenting easier (Chen et al. 2019).

\section{Acknowledgements}

This work was supported by a grant from the Russian Science Foundation (project №19-1800271).

\section{References}

Barber, B. K. and Harmon, E. L. (2002). Violating the self: Parental psychological control of children and adolescents. American Psychological Association.

Bitsko, R. H., Holbrook, J. R., Ghandour, R. M., Blumberg, S. J., Visser, S. N., Perou, R., and Walkup, J. T. (2018). Epidemiology and impact of health care provider-diagnosed anxiety and depression among us children. Journal of developmental and behavioral pediatrics: $J D B P, 39(5): 395$.

Brent, D. A., Emslie, G. J., Clarke, G. N., Asarnow, J., Spirito, A., Ritz, L., Vitiello, B., Iyengar, S., Birmaher, B., Ryan, N. D., et al. (2009). Predictors of spontaneous and systematically assessed suicidal adverse events in the treatment of ssri-resistant depression in adolescents (tordia) study. American Journal of Psychiatry, 166(4):418-426.

Burdzovic, J. and Brunborg, G. S. (2017). Depressive symptomatology among norwegian adolescent boys and girls: the patient health questionnaire-9 (phq-9) psychometric properties and correlates. Frontiers in psychology, 8:887.

Chen, Y., Haines, J., Charlton, B. M., and VanderWeele, T. J. (2019). Positive parenting improves multiple aspects of health and well-being in young adulthood. Nature human behaviour, 3(7):684-691.

Dardas, L. A., van de Water, B., and Simmons, L. A. (2018). Parental involvement in adolescent depression interventions: A systematic review of randomized clinical trials. International journal of mental health nursing, 27(2):555-570.

Davids, E. L., Roman, N. V., and Leach, L. (2017). The link between parenting approaches and health behavior: A systematic review. Journal of Human Behavior in the Social Environment, 27(6):589-608.

Fröjd, S., Kaltiala-Heino, R., and Rimpelä, M. (2007). The association of parental monitoring and family structure with diverse maladjustment outcomes in middle adolescent boys and girls. Nordic Journal of Psychiatry, 61(4):296-303.

Grolnick, W. S. and Pomerantz, E. M. (2009). Issues and challenges in studying parental control: Toward a new conceptualization. Child Development Perspectives, 3(3):165-170. 
Hale, W. W., VanderValk, I., Akse, J., and Meeus, W. (2008). The interplay of early adolescents' depressive symptoms, aggression and perceived parental rejection: A four-year community study. Journal of Youth and Adolescence, 37(8):928-940.

Im, M. H., Hughes, J. N., and West, S. G. (2016). Effect of trajectories of friends' and parents' school involvement on adolescents' engagement and achievement. Journal of Research on Adolescence, 26(4):963-978.

Kroenke, K., Spitzer, R. L., Williams, J. B., and Löwe, B. (2010). The patient health questionnaire somatic, anxiety, and depressive symptom scales: a systematic review. General hospital psychiatry, 32(4):345-359.

Lambert, M., Fleming, T., Ameratunga, S., Robinson, E., Crengle, S., Sheridan, J., Denny, S., Clark, T., and Merry, S. (2014). Looking on the bright side: An assessment of factors associated with adolescents' happiness. Advances in Mental Health, 12(2):101-109.

Lawrence, D., Johnson, S., Hafekost, J., Boterhoven de Haan, K., Sawyer, M., Ainley, J., and Zubrick, S. R. (2015). The mental health of children and adolescents: Report on the second Australian child and adolescent survey of mental health and wellbeing. Department of Health.

Leung, D. Y., Mak, Y. W., Leung, S. F., Chiang, V. C., and Loke, A. Y. (2020). Measurement invariances of the phq-9 across gender and age groups in chinese adolescents. Asia-Pacific Psychiatry, 12(3):e12381.

Norman, R. E., Byambaa, M., De, R., Butchart, A., Scott, J., and Vos, T. (2012). The long-term health consequences of child physical abuse, emotional abuse, and neglect: a systematic review and meta-analysis. PLoS med, 9(11):e1001349.

Rengasamy, M., Mansoor, B. M., Hilton, R., Porta, G., He, J., Emslie, G. J., Mayes, T., Clarke, G. N., Wagner, K. D., Keller, M. B., et al. (2013). The bi-directional relationship between parent-child conflict and treatment outcome in treatment-resistant adolescent depression. Journal of the American Academy of Child $\& 3$ Adolescent Psychiatry, 52(4):370377.

Rueter, M. A., Scaramella, L., Wallace, L. E., and Conger, R. D. (1999). First onset of depressive or anxiety disorders predicted by the longitudinal course of internalizing symptoms and parent-adolescent disagreements. Archives of General Psychiatry, 56(8):726-732.

Sheeber, L. B., Davis, B., Leve, C., Hops, H., and Tildesley, E. (2007). Adolescents' relationships with their mothers and fathers: associations with depressive disorder and subdiagnostic symptomatology. Journal of abnormal psychology, 116(1):144.

Shelton, K. K., Frick, P. J., and Wootton, J. (1996). Assessment of parenting practices in families of elementary school-age children. Journal of clinical child psychology, 25(3):317329.

Soenens, B. and Vansteenkiste, M. (2010). A theoretical upgrade of the concept of parental psychological control: Proposing new insights on the basis of self-determination theory. Developmental Review, 30(1):74-99. 
Spitzer, R. L., Kroenke, K., Williams, J. B., Group, P. H. Q. P. C. S., Group, P. H. Q. P. C. S., et al. (1999). Validation and utility of a self-report version of prime-md: the phq primary care study. Jama, 282(18):1737-1744.

Stice, E., Ragan, J., and Randall, P. (2004). Prospective relations between social support and depression: Differential direction of effects for parent and peer support? Journal of abnormal psychology, 113(1):155.

Tammariello, A. E., Gallahue, N. K., Ellard, K. A., Woldesemait, N., and Jacobsen, K. H. (2012). Parental involvement and mental health among thai adolescents. Advances in School Mental Health Promotion, 5(4):236-245.

Tsehay, M., Necho, M., and Mekonnen, W. (2020). The role of adverse childhood experience on depression symptom, prevalence, and severity among school going adolescents. Depression research and treatment, 2020.

Walters, G. D. (2019). Mothers and fathers, sons and daughters: Parental knowledge and quality of the parent-child relationship as predictors of delinquency in same-and cross-sex parent-child dyads. Journal of Child and Family Studies, 28(7):1850-1861.

Wells, T. S., Horton, J. L., LeardMann, C. A., Jacobson, I. G., and Boyko, E. J. (2013). A comparison of the prime-md phq-9 and phq- 8 in a large military prospective study, the millennium cohort study. Journal of affective disorders, 148(1):77-83.

WHO (2008). The global burden of disease: 2004 update. World Health Organization.

Yap, M. B. H., Pilkington, P. D., Ryan, S. M., and Jorm, A. F. (2014). Parental factors associated with depression and anxiety in young people: A systematic review and metaanalysis. Journal of affective disorders, 156:8-23.

Young, C. B., Fang, D. Z., and Zisook, S. (2010). Depression in asian-american and caucasian undergraduate students. Journal of affective disorders, 125(1-3):379-382.

\section{Affiliation:}

Ksenia Pavlenko

HSE University

Moscow, Russia

E-mail: kpavlenko@hse.ru

\section{SocArXiv Website SocArXiv Preprints}

Preprint

URL/DOI GOES HERE https://socopen.org/

https://osf .io/preprints/socarxiv

Submitted: November 20, 2021

Accepted: November 20, 2021 